\title{
POLÍTICAS URBANAS: A ENCRIPTAÇÃO DO DIREITO E A DESENCRIPTAÇÃO PELA APLICAÇÃO DA IDEOLOGIA CONSTITUCIONAL ADOTADA
}

\section{URBAN POLICIES: THE ENCRYPTATION BY RIGHT AND THE DECODED BY THE USE OF THE ADOPTED CONSTITUTIONAL IDEOLOGY}

\author{
${ }^{1}$ Giovani Clark \\ ${ }^{2}$ Bruno Fernandes Magalhães Pinheiro de Lima
}

\section{RESUMO}

$\mathrm{O}$ artigo pretende discutir a ausência da efetividade qualitativa das políticas urbanas brasileiras baseadas no artigo 182 da $\mathrm{CF} / 88$ e nos instrumentos presentes na Lei $\mathrm{n}^{\circ}$ 10.257/2001. Como hipóteses propõem-se: (i)que esta ausência se dá em decorrência da encriptação de poder pelo direito que operacionaliza o planejamento urbano em simulacro democrático; (ii)que a leitura jurídica com base na ideologia constitucional adotada é capaz de desencriptar o direito e possibilitar a re-apropriação democrática do planejamento urbano brasileiro. A pesquisa é documental apoiada na doutrina e na legislação pertinente, tendo como principais referenciais teóricos Sanín Restrepo e Washington Peluso Albino de Souza.

Palavras chave: planejamento urbano; encriptação; ideologia constitucional adotada; crise urbana; neoliberalismo.

\begin{abstract}
This paper intent to discuss the absence of qualitative effectiveness of the Brazilian urban policies based on article 182 of Constitution and on the legal instruments presents in Law $\mathrm{n}^{\circ}$ 10.257/2001. Hypotheses proposed are: (i)that this absence occurs due to the encryption of power by right which operationalize urban planning in democratic simulacrum; (ii)legal reading based on the adopted constitutional ideology is able to decoded the law and enable the democratic re-appropriation of urban planning. The research is based on legal doctrine and on the relevant legislation, having as main theoretical references Sanín Restrepo and Washington Peluso Albino de Souza.
\end{abstract}

Keywords: urban planning; encryptation; adopted constitutional ideology; urban crisis; neoliberalism.

\footnotetext{
${ }^{1}$ Doutor em Direito Econômico, Professor do Programa de Pós-graduação em Direito pela Pontifícia Universidade Católica (PUC) Belo Horizonte, Minas Gerais. Docente Faculdade de Direito pela Universidade Federal de Minas Gerais (UFMG), Belo Horizonte, Minas Gerais, Brasil. Email: giovaniclark@gmail.com

${ }^{2}$ Geógrafo. Advogado e Mestrando do Programa de Pós-graduação em Direito pela Pontifícia Universidade Católica (PUC), Belo Horizonte, Minas Gerais, Brasil. Email: brunofmpl@gmail.com
} 


\section{INTRODUÇÃO}

O tema objeto do trabalho é discutir e analisar a função pública do planejamento na atuação do Estado brasileiro na elaboração e promoção de políticas estatais no âmbito das políticas urbanas.

O artigo parte do problema que as políticas urbanas não estão alcançando seus objetivos, reproduzindo as desigualdades e problemas configuradas na permanente "crise urbana" brasileira que os artigos 182 e 183 da Constituição Federal de 1988 e a Lei no 10.253 de 10 de julho de 2001 - Estatuto da Cidade - pretendem combater. Ou seja, a distorção se fundamenta na contradição evidente entre aplicação dos marcos normativos e seus efeitos concretos contraditórios aos desejados pela ordem normativa e constitucional, ou seja, a não eficácia daqueles .

Desse modo, estabelece como hipótese que a contradição entre o aumento da aplicação dos instrumentos de política urbana, especialmente a Operação Urbana Consorciada previstos no Estado da Cidade e a ampliação da "crise urbana" brasileira, se deve ao modelo de planejamento estatal (re)produzido globalmente com base nos modelos de governança urbana empreendedora que afastariam as demandas urbanas populares e plurais, precarizando o interesse público, em prol de privilégios privados.

Metodologicamente a pesquisa que sustenta o artigo se orientou pela prospecção bibliográfica no intuito de desvelar os significados de planejamento estatal para assim confrontá-los com o planejamento público brasileiro (real) na concretização de políticas estatais urbanas, percebidas através dos dados primários e secundários produzidos por pesquisas do Instituto Brasileiro de Geografia e Estatística - IBGE - e Instituto de Pesquisa Econômica e Aplicada - IPEA. Assim sendo, a pesquisa é eminentemente documental apoiada na doutrina e na legislação pertinente, tendo como principais referenciais teóricos Ricardo Sanín Restrepo e Washington Peluso Albino de Souza.

\section{A "crise urbana" brasileira}

Em que consiste a "crise urbana" brasileira? Defendemos que os problemas no setor urbano brasileiro consiste na produção e aplicação dos marcos legais referentes às políticas urbanas e seus resultados efetivos contraditórios à paisagem normativa desenhada por tais marcos legais, em razão das possibilidades oferecidas pelo direito encriptado, digo, em 
deslocar os objetivos destas políticas dos interesses sociais e públicos para os interesses privados do mercado.

Desde a redemocratização, tendo como marco temporal essencial a Constituição brasileira, os textos normativos acerca do espaço urbano brasileiro se multiplicam. Esta tendência de normatização dos direitos associados à cidade não é uma exclusividade brasileira, conforme aponta Osório (2013, p. 2), sendo também um processo comum na América Latina. Curiosamente, os resultados da normatização e sua aplicação em todo continente Latino Americano parecem ser similares: ou seja, refletem, como no Brasil, um quadro de "crise permanente".

No Brasil, além da nossa Lei Maior de 1988 e seu capítulo de Política Urbana, assim como os espectros de direitos urbanos difusos no texto constitucional, mas diretamente percebidos nos artigos $5^{\circ}, 6^{\circ}, 182$ e 225, destacam-se duas legislações, são elas: Lei n ${ }^{\circ} 10.257$ de 10 de julho de 2001 - Estatuto da Cidade e a Lei no 11.977 de 07 de julho 2009 Programa Minha Casa, Minha Vida - PMCMV. A primeira lei foi fundamental para a consolidação dos instrumentos políticos-jurídicos de planejamento urbano, já a segunda é o "principal" marco normativo associado à regularização fundiária e direito à moradia da nação.

Os dispositivos normativos mais pertinentes ao trabalho estão no Estatuto da Cidade, especificamente o artigo $2^{\circ}$, pois estabelece as diretrizes das políticas urbanas para o ideal normativo e político do espaço urbano brasileiro (também desveláveis do Texto Constitucional, por meio da leitura dos artigos $5^{\circ}, 6^{\circ}, 182$ e 225). Em síntese, o dito dispositivo normativo (art. $2^{\circ}$ ) determina que as políticas urbanas devem apresentar três fundamentos: (i) construir cidades sustentáveis, ou seja, que apresentem desenvolvimento econômico capaz de gerar riquezas e reduzir desigualdades produzindo baixos impactos negativos ambientais e sociais (incisos: I, IV, V, VI, VII, VIII, IX, XII e XIV); (ii) ser planejadas de forma democrática, através de processos administrativos que estejam condicionados à participação popular (incisos II, X e XIII); e (iii) ser consorciadas, ou seja, os investimentos necessários para o desenvolvimento das políticas podem ou devem ser realizados em parceria com a iniciativa privada, retirando, portanto, a exclusividade do setor público (incisos III, XV e XVI).

Diante do cenário político-jurídico apresentado, esperava-se que nos últimos anos, como resultado do avanço da legislação a qualidade de vida nas cidades brasileiras melhorasse. Entretanto não foi isto o que ocorreu. Neste momento cabe mais uma vez salientar: o problema pesquisado parte basicamente da constatação que a "crise urbana" brasileira não se dá pela inexistência dos instrumentos de políticas urbanas, mas de suas 
aplicações, sobretudo pelas administrações municipais, ou seja, ineficácia da lei. O Prof. Paulo Dourado Gusmão (1998) versa sobre a diferença em vigência e eficácia:

\begin{abstract}
.... no sentido técnico-jurídico vigência é a dimensão temporal e espacial da obrigatoriedade do direito, determinável, começando da data em que for publicado a lei no Diário Oficial, ou da data nela prevista, terminando na data de sua revogação total ou parcial, expressa ou tácita, quando lei posterior dispuser em sentido contrário. Vigente, assim, a lei sancionada e publicada no Diário Oficial, enquanto não revogada, ou o tratado internacional, aprovado por decreto legislativo, enquanto não denunciado ( $p$. 58.).

A eficácia (Getung) do direito depende do fato de sua observância no meio social no qual é vigente. Eficaz é o direito efetivamente observado e que atinge a sua finalidade. É assim, um fato, consistindo na observância efetiva da norma por parte de seus destinatários e, no caso de inobservância, na sua aplicação compulsória pelos órgãos com competência para aplicá-la (Judiciário, Administração Pública, Polícia, etc). Significa, com palavras de Kelsen, direito que é "realmente aplicado e obedecido"( p. 59).
\end{abstract}

Entre o período de 2005 a 2013, os municípios que possuíam Plano Diretor passaram de 805 em 2005 para 2.785 em 2013; ou seja, de 14,47\% dos municípios brasileiros, para 50\% dos municípios com Planos Diretores. Os municípios que contavam com previsão de Operação Urbana Consorciada - OUC, por exemplo, eram 393 em 2005, sendo que este número praticamente triplicou em 2013 ao alcançar 1.038 municípios brasileiros. A utilização de legislação para zoneamento e uso do solo, outro tipo de instrumento, também cresceu consideravelmente, pois em 2005 apenas 1.144 municípios contavam com este tipo de legislação, contudo em 2013, 3.021 municípios já tinham algum tipo de legislação de zoneamento, uso e ocupação do solo (IBGE, 2006; IBGE 2014).

Entretanto, apesar da ampla operacionalização pelas administrações públicas locais (incluindo os estaduais e federais) dos marcos normativos supracitados, as desigualdades e injustiças da estrutura urbana brasileira permanecem inalteradas ou com pequenas variações que revelam a ineficácia dos textos normativos ou suas incompletudes.

O primeiro exemplo sobre a suposta insuficiência das políticas públicas pode ser compreendido a respeito do crescimento da população em aglomerados subnormais nas áreas urbanas brasileiras. Em 2000, 4,67\% da população urbana residia em aglomerados subnormais, em 2010, este contingente populacional passou a compor $12,82 \%$ da população urbana nacional (NADALIN; KRAUSE; LIMA NETO, 2016, p. 80). Ou seja, a despeito da melhoria na distribuição de renda no período 2003-2013, com o aumento da renda e emprego para grande parte da população brasileira, as políticas urbanas de habitação não lograram êxito em produzir melhores cidades, contribuindo para a continuidade da reprodução da desigualdade territorial (MORADO NASCIMENTO, 2014, p.118). 
Outro aspecto que denuncia a falta de eficácia das políticas urbanas corresponde às políticas habitacionais associadas às políticas de mobilidade. A expansão geográfica dos centros urbanos instituído via ações habitacionais no modelo créditos financeiros subsidiados pelo Estado afim de aquisição de unidades residenciais, construídas principalmente pelo setor privado (ROLNIK, 2015, p.34) oneram, por meio do sistema de transporte (utilização das linhas com tarifas mais caras), de forma desigual, as populações mais pobres das cidades brasileiras (MOURA; PÊGO, 2016, p.55).

Por fim, há o exemplo das políticas derivadas dos modelos de privatização é a recente difusão da Operação Urbana Consorciada - OUC - como principal política pública de planejamento urbano. Pesquisas indicam (COTA, 2011, p.152; FIX, 2009, p. 51; MONTANDON, 2009, p.2) que a realização da OUC não corresponde aos interesses sociais e públicos que a deu origem, assim como gera efeitos contrários como a gentrificação e concentração de renda nas áreas em que foi promovida. FIX $(2009$, p.52) demonstra que as OUC's de São Paulo tem contribuído um cenário de gentrificação, reduzindo a densidade populacional das áreas das OUC's, enquanto a renda destes espaços urbanos crescem - ao mesmo tempo, em razão do encarecimento das condições materiais de vida nos ditos espaços, já a população ao redor têm acréscimo demográfico e decréscimo de renda. Ou seja, configuram a gentrificação, pois expulsam a população original da área da OUC pelo encarecimento das condições materiais de vida (ou simplesmente processos de desapropriação), enquanto as áreas da OUC's, requalificadas com investimentos públicos e privados servem aos novos moradores com poder financeiro superior.

Logo, é diante das incoerências concretas apresentadas que se defende a existência de uma "crise urbana". "Crise" que não se dá pelos processos de violência urbana, exclusivamente, como aqueles teatralizados pelo circo do jornalismo brasileiro (grande mídia), mas sim pela utilização cada vez mais crescente e competente de marcos normativos (pelos empoderados) que deveriam, supostamente, produzir efeitos alinhados com a justiça territorial.

\section{0 significado (jurídico) de planejamento estatal}

O planejamento é correntemente associado a noção de ação racional. Não se trata aqui de estabelecer uma reflexão sobre os diversos significados de razão (SANTOS, 2008, p. 140), mas de reconhecer o significado de planejamento e seu sentido no Direito, sobretudo por ser um poder/dever estatal. 
Planejamento possui como significado genérico de ação racional do Estado para a concretização de objetivos socialmente-politicamente definidos (FRIEDMAN, 1987, p. 51 e SOUZA, 2008, p. 372). Esta perspectiva de ação racional, produzida a partir de um conjunto de informações científicas é, inclusive, traduzida no direito pela diferenciação entre plano e planejamento estabelecida por SOUZA (2005, p. 372).

Apesar do significado relacionado à intervenção estatal, cabe destacar que há uma diversidade de perspectivas acerca das possibilidades daquela. Há diversas teorias de planejamento, todas definidas a partir de teorias políticas - da direita à esquerda radical, que orientam a forma de construir a suposta ação racional do Estado (FRIEDMAN, 1987, p.52).

Teóricos do planejamento associados ao campo liberal comumente propõe ações estatais planejadas por intervenções que estimulem o funcionamento livre do mercado, enquanto noções associadas à esquerda, propõe o contrário (no Estado). Interessante notar que durante anos de evolução das teorias de planejamento, recentemente, desde a derrocada do "Estado do Bem Estar Social", tanto as teorias liberais, quanto as teorias revolucionárias, caminharam para a construção de um planejamento dissociado do protagonismo estatal (FRIEDMAN, 1987, p.53).

Considerando que o planejamento (CAAMARGO, 2014, p. 174) é dever estatal para a promoção de políticas públicas a fim de efetivar a constituição, é inevitável não concluir pelo seu aspecto político. Logo, a despeito de leituras mais tecnicistas, especialmente pelo campo da direita (FRIEDMAN, 1987, p. 55), é necessário reconhecer o plano político no qual se desvela o planejamento e como se concretiza na e para a sociedade.

O significado jurídico de planejamento só pode ser desvelado a partir da leitura dos textos normativos. Desse modo é fundamental a contribuição de Souza (2005, p. 371) que procura recuperar o significado jurídico a partir dos textos normativos, evitando a perda dos aspectos políticos que subsidiam o planejamento e ação estatal.

Para Souza (2005, p.372) o planejamento estatal só pode ser compreendido a partir da relação entre plano e a planificação (ato de planejar). A planificação consiste na racionalização dos meios disponíveis para deles retirar os efeitos mais favoráveis, sendo esta racionalização possível apenas se baseada em determinação política. O ato de planejar é operacionalizado pelo plano, considerado como o documento ou peça técnica que subsidia o ato de planejar, ao mesmo tempo em que o dá origem (SOUZA, 2005, p. 372). Ou seja, o plano para Souza (2005), é origem e resultado da ação de planejar.

O vínculo jurídico do planejamento, por sua vez, é extraído da normatização do plano. Apesar de Souza (2005, p. 372) descrever apenas como vinculado juridicamente os planos que 
adquirem forma de lei (SOUZA, 2005, p. 373), devemos considerar, apenas para evitar incompreensões deste mesmo autor, que os planos derivados de previsão normativa, também vinculadoras da administração pública.

O plano, portanto, modulam a intervenção estatal. Mas, a despeito de qualquer resultado da legislação planejadora, estes nunca podem ser compreendidos de forma fechada. Pois conforme nos demonstra Souza (2005, p. 28-29), é preciso considerar a ideologia constitucional adotada que confere conteúdo aos planos e orientam os atos de planejar. Explica Souza (2005) sobre ideologia constitucionalmente adotada:

\footnotetext{
Não se trata do sentido filosófico ou político amplo, de ideologia, nem mesmo de cada ideologia política geralmente referida, tal como a capitalista, a socialista, a comunista, etc. Independentemente dessa configuração, referimo-nos aos princípios que sejam fundamentais na ordem jurídica considerada, mesmo que isoladamente se identifiquem com alguma daquelas ideologias políticas acima referidas.

A ideologia a que nos referimos é aquela definida, em Direito Positivo, no Estado de Direito, pela Constituição vigente, em cada época e em cada país. Por isso, a definimos como "ideologia constitucionalmente adotada". Fica estabelecida, pois, a diferença entre esta e a que se possa entender por ideologia dos modelos teóricos tradicionais, ou seja, conjuntos de idéias, de princípios ou de teorias destinados a explicar, abstratamente, a organização social, a estrutura política e assim por diante. De modo geral, em se tratando da presença dos temas econômicos nas Constituições modernas, boa parte dos elementos considerados como correspondentes a esse conceito de ideologia estão reunidos no capítulo da "Ordem Econômica e Social", que por essa razão é denominado "Constituição Econômica", apesar de muitos deles também se encontrarem dispersos por outras partes do texto constitucional (SOUZA, 2005, p.28-29).
}

A ideologia constitucional adotada consiste no parâmetro hermenêutico segundo o qual o intérprete, ao analisar a juridicização da política deve condicionar-se aos fundamentos normativos-axiológicos positivados na Constituição (CLARK; CORRÊA; NASCIMENTO, 2013, p. 269). Logo, ela desvela a amplitude política do texto normativo com base na contextualização global do texto em todo o conjunto normativo.

Portanto, considerando o conteúdo amplo da ordem normativa brasileira, especialmente os dispositivos normativos referentes ao direito à cidade e planejamento urbano, concluímos que o significado jurídico de planejamento deve ser entendido como o conteúdo político, diretivo, mas plural, que organiza a dita intervenção estatal.

\section{Encriptação de poder: leituras do planejamento estatal a partir do direito.}

Apesar da (re)significação do plano e planejamento a partir da noção de ideologia constitucional adotada, além do próprio conteúdo das legislações urbanísticas, o cenário que se apresenta é o de "crise urbana", conforme percebido pelos dados apresentados 
anteriormente de ampliação das políticas urbanas planejadas (legislação)e seus efeitos contraditórios.

Como hipótese principal, propomos que a crise urbana conforme discutida se dá em razão da encriptação de poder operacionalizada pelo direito no modelo oferecido por SANÍN RESTREPO (2014, p.14), que simula a democracia de forma a privilegiar o poder econômico e político sintetizada pela ideia de Império (HARDT; NEGRI, 2010, p.220).

A encriptação de poder consiste na desarticulação política da democracia reduzindo todos os conflitos às formas jurídicas que seriam manipuladas por jogos de linguagem retirando do povo (oculto) a capacidade de discutir politicamente e juridicamente os conflitos que vivem, sendo estes conflitos reduzidos às formas preferidas pelo poder constituído. Assim a encriptação de poder se dá pela operacionalização das formas jurídicas para dominação e ocultação de poder popular, sendo que supõe:

(...) en primer lugar, un enmarañamiento progresivo del lenguaje de la
interpretación, no solo de la constitución y la ley, sino además de las imágenes y
todas las cadenas de información que "constituyen" la realidad. En segundo lugar la
encriptación arrebata la realidad misma del sentido y los saberes comunes hasta
convertirlo en capital exclusivo de expertos. Tercero, se trata de un desplazamiento
de las líneas de decisión donde sucesivamente las decisiones suceden cada vez
menos en foros políticamente abiertos y cada vez más en foros expertos sustraídos
de la más elemental regla de la responsabilidad de las discusiones públicas, donde
los actos del poder son visibles, pero son ininteligibles. (SANÍN RESTREPO, 2014,
p. 207).

Logo, na encriptação de poder a democracia se torna um simulacro que permite reconhecer direitos ao mesmo tempo em que os nega de forma parcial ou total e automática, em razão da instrumentalidade do direito pelo poder constituído (MENDEZ HINCAPIE; SANÍN RESTREPO, 2012, p.33).

A encriptação de poder é fundamental ao trabalho, pois, propomos que é com base na encriptação de poder que a política urbana brasileira se assenta sobre simulacros de democracia, desarticulando o planejamento urbano democrático e, portanto, se realizando apenas como instrumento do mercado. Ademais, as políticas urbanas delimitadas pelas formas jurídicas se transformariam em:

(...) una simulación simbólica, el antagonismo es renegado a calificaciones estrictas en las que se desarticulan y aplazan las demandas populares y se retien la posibilidad de que las partes débiles o invisibles usen lenguaje que no sea el de la parte fuerte de la institucionalidad (SANÍN RESTREPO, 2012, p. 33). 
O simulacro de democracia contamina a realização democrática do planejamento urbano e, portanto, de suas políticas, tendo relação direta com os elementos da dominação sob a forma de Império (HARDT; NEGRI. 2010, p. 220). A relação entre o poder do Império e a modulação das políticas urbanas será discutida a seguir, ao apresentarmos a supremacia do mercado na formulação daquelas.

Assim por meio da encriptação as políticas urbanas são destituídas de suas bases democráticas e controladas pelos atores sociais que detém o poder político e econômico. $\mathrm{Ou}$ seja, as políticas não concretizam os interesses sociais e públicos que as conferem validade, por serem cooptadas/ditadas pelo poder econômico simulando os direitos democráticos à cidade com base no artigo $2^{\circ}$ do Estatuto da Cidade.

O simulacro por meio da cooptação/imposição dos atores institucionais e encriptação de poder fica evidente nos grandes projetos urbanos em que a função social da propriedade, por exemplo, autoriza e legitima processos de desapropriação das populações de baixa renda, gentrificando áreas de Operações Urbanas Consorciadas (FIX, 2009, p.60), mas o mesmo dispositivo constitucional de função social da propriedade, a despeito de regulamentação constitucional e infraconstitucional, não consegue viabilizar desapropriações de imóveis desocupados para fins de moradia (FERNANDES LIMA, 2015, p.34).

A partir da encriptação (SANÍN RESTREPO, 2014, p.207), o direito é manipulado de forma a "validar" e realizar apenas os interesses de determinados atores sociais, gerando a ineficácia da Constituição, principalmente para trabalhadores, sem tetos, inquilinos residenciais e excluídos. Ou seja, a "crise urbana" não é um erro, mas sim um acerto, ela existe não porque o direito encriptado não funciona adequadamente, mas porque ele funciona como foi tabulado.

\section{Planejamento estatal na reestruturação do Estado brasileiro pós Constituição de 1988.}

A nossa Constituição da República é o marco político e jurídico fundamental na reestruturação administrativa e social do Estado brasileiro. Resultado de um longo processo político marcado pela a opressão e ao mesmo tempo de pressões pela modernização. Ela representa a confluência de lutas e resistências de diversos setores da sociedade brasileira.

É após a Lei Maior de 1988 que se dá a reestruturação da função planejamento do Estado brasileiro. Esta reestruturação de certa forma incorpora ideologias distintas, construindo comandos normativos plasmando uma ideologia constitucional adotada plural (SOUZA, 2005, p.28-29; CLARK, CORRÊA, NASCIMENTO, 2013, p. 280). Destacamos 
que, apesar dos avanços das teorias de planejamento progressistas, como, por exemplo, pela ampliação da participação popular por meio dos Orçamentos Participativos, as teorias neoliberais reguladoras são as hegemônicas e principais na realidade brasileira (MAGALHÃES, 2015, p 109).

A reestruturação do Estado brasileiro se deu, na perspectiva jurídica e institucional, a partir da elaboração e operacionalização de marcos normativos que sintetizaram as teorias reguladoras. O planejamento neoliberal regulador consiste na modificação da forma de intervenção do Estado na sociedade, possuindo como principal elemento a privatização da esfera pública estatal, especialmente aqueles referentes à função de formulação e execução da legislação planejadora. Seus pilares são as privatizações das empresas e serviços públicos e a incorporação das diretrizes (normas jurídicas) pertinentes ao mercado.

Durante a guerra fria, no século passado (1945 a 1990), imperou na economia de mercado às políticas econômicas neoliberais de regulamentação, onde o Estado Nacional transfigurou-se em Social, realizando a sua atuação no domínio econômico diretamente, via empresa pública, sociedade de economia mista e fundações; e indiretamente, através das normas legais de direito. Tudo em nome do desenvolvimento ou do crescimento.

Naqueles tempos de regulamentação, os capitais privados eram investidos internacionalmente na indústria de consumo, mas também na rendosa indústria armamentícia. Assim sendo, o poder econômico privado nacional e internacional precisava da ação estatal em setores de baixa lucratividade, de riscos financeiros ou carentes de vultosos investimentos tecnológicos, como ás áreas de infra-estrutura (energia, estradas, água potável, telefonia) e social (educação, saúde, previdência), a fim de possibilitar o progresso da economia de mercado, refrear os movimentos sociais reivindicativos (dos trabalhadores, por exemplo) e remover o fantasma do socialismo. Dessa forma, se norteavam as ações econômicas públicas reservando a iniciativa privada ampliação de seus ganhos.

No fim do século XX e no início do século XXI, as políticas neoliberais de regulamentação passaram a restringir a expansão e a mobilidade do capital. O novo ambiente mundial de fim da guerra fria, queda do socialismo real e de alta evolução tecnológica resulta em pressões por outras políticas econômicas ao gosto dos donos do capital. Os Estados nacionais passam a executar o neoliberalismo de regulação transferindo serviços e atividades econômicas estatais á iniciativa privada (via privatização e desestatização), agora, atraentes ao capital, em face da "redução" dos ganhos com a indústria bélica da guerra fria e dos avanços científicos. A tecnologia tornou lucrativos setores que anteriormente tinham baixa lucratividade, ou não tinham, e estavam nas mãos do Estado (CLARK, 2008, p. 70)

Os aspectos citados anteriormente podem ser compreendidos com base na breve análise dos marcos normativos que vincularam e influenciaram a administração pública brasileira. Os primeiros marcos normativos estão relacionados ao Programa Nacional de Desestatização, representados pela Lei $\mathrm{n}^{\circ}$ 8.031, de 12 de abril de 1990, revogada pela Lei $\mathrm{n}^{\circ}$ 9.491, de 9 de setembro de 1997. Neste programa a tendência de redução da intervenção do Estado na economia brasileira se deu pela transferência de ativos (empresas estatais e serviços 
públicos) para a iniciativa privada. A privatização foi amplamente difundida em todo o globo nas décadas de 1980 e 1990, sendo que a América Latina foi o principal laboratório das políticas neoliberais reguladoras, através da atuação expansiva e invasiva do Fundo Monetário Internacional - FMI.

Outro marco normativo fundamental para a lógica reguladora de intervenção estatal foi a Lei Complementar $n^{\circ} 101$ de 4 de maio de 2000 - Lei de Responsabilidade Fiscal - LRF. A famosa LRF trouxe a suposta dignidade e moralidade para a administração pública ao organizar e limitar os investimentos orçamentários, especialmente com burocracia estatal (pessoal) e serviços públicos. Por outro lado, a LRF procura priorizar os gastos destinados ao pagamento de credores em vez daqueles relacionados às funções e objetivos do Estado brasileiro na concretização do desenho de cidadania fixado no texto constitucional.

Por fim, o principal e definitivo marco normativo na guinada neoliberal reguladora é a Lei ${ }^{\circ} 11.079$ de 30 de dezembro de 2004 - Lei da Parceria Público Privada - PPP. A Lei da PPP é fundamental para o contexto regulador do Estado brasileiro, porque ela literalmente permite a transferência não apenas dos serviços, mas do planejamento na execução de serviços e obras. As modalidades de PPP previstas em seu artigo $2^{\circ}$ (Lei n. 11.079/2004) permitem que o Estado saia do protagonismo parcial ao derreter a construção de políticas com base nos interesses do mercado. Ou seja, a forma de viabilizar investimentos públicos passa pelo interesse do mercado (empresas), esvaziando as demandas socioeconômicas, os ditames constitucionais e o papel estatal. Os orçamentos públicos são instrumentalizados em parte por meio da captação de recursos no mercado, condiciona os investimentos aos interesses do capital. Recentemente, tivemos ainda, seguindo a mesma trilha, a União editou a Medida Provisória 727, de 12 de maio de 2016, aprofundando a "nova" faceta do neoliberalismo, digo de austeridade, criando o programa de parcerias de investimentos - PPI.

A reconfiguração da intervenção estatal com base nos marcos normativos citados demonstra a nítida guinada neoliberal reguladora (CLARK, 2012, p. 149), pois estes constroem um ambiente jurídico e político que vinculam as atividades estatais aos interesses de mercado, como se estes fossem absolutos e intocáveis pelos comandos constitucionais.

\section{A privatização das políticas públicas urbanas e a desfuncionalização da democracia a partir do significado de Ideologia Constitucional Adotada}

A reconfiguração neoliberal reguladora descrita acima, evidentemente, encontra respaldo na política urbana brasileira. A necessidade de administrar para o mercado é 
acertadamente sintetizada por Harvey pelo significado de governança urbana empreendedora, nos seguintes termos:

Em primeiro lugar, o novo empreendedorismo tem, como elemento principal, a noção de "parceria-público privada", em que a iniciativa tradicional local se integra com o uso dos poderes governamentais locais, buscando e atraindo fontes externas de financiamento, e novos investimentos diretos ou novas fontes de emprego.

(...)

Em segundo lugar, a atividade da parceria público-privada é empreendedora, pois, na execução e no projeto, é especulativa, e portanto, sujeita a todos os obstáculos e riscos associados ao desenvolvimento especulativo, ao contrário do desenvolvimento racionalmente planejado e coordenado.

(...)

Em terceiro lugar, o empreendedorismo enfoca muito mais a economia política do lugar do que o território. Em relação ao território, penso nos projetos econômicos (moradia, educação etc) idealizados principalmente para melhorar as condições de moradia ou trabalho de uma jurisdição específica (HARVEY, 2005, p. 172-173)

Os modelos de planejamento (legislação) que priorizam as lógicas privadas de produção do espaço são amplamente influenciados pelos organismos internacionais de financiamento. A suposta "ausência" de recursos da administração pública, seja por má gestão, seja redução de tributos aos ricos ou por subserviência à lógica do mercado regulador - como o enquadramento subalterno presente na LRF - faz com que as administrações estatais recorram inevitavelmente as fontes privadas de financiamento.

No plano internacional, SWYNGEDOUW (2004, p. 46), os organismos de financiamento internacional, Banco Mundial e Banco Interamericano de Desenvolvimento, vinculam a concessão de empréstimos para obras de infraestrutura, como fornecimento de água, à privatização do serviço, ao cumprimento dos ditames neoliberais.

É neste contexto que as políticas urbanas brasileiras se desenvolveram a partir da Constituição da República de 1988. Em face do Estatuto da Cidade as funções da cidade puderam ser capturadas/ditadas pelos interesses do mercado com base na privatização do planejamento urbano, inclusive por intermédio (atrelada) da Operação Urbana Consorciada OUC.

A OUC está prevista entre os artigos 32 a 34 do Estatuto da Cidade, basicamente, consiste em um instrumento de planejamento urbano centrado na colaboração entre administração pública, iniciativa privada (investidores e proprietários) e sociedade civil, com o objetivo de reestruturar do território, sendo possível alterar parâmetros legais de acordo com os objetivos e interesses locais (incisos I, II e III do $\$ 2^{\circ}$ do artigo 32 do Estatuto da Cidade).

Como demonstrado anteriormente, o crescimento do número de municípios que utilizam a OUC, considerando a suposta crise financeira do Estado, aponta para a conclusão óbvia que tal instrumento de política urbana está se consolidando como a principal ferramenta 
de investimentos públicos nas cidades brasileiras. Ao lado desta conclusão, apresenta-se outra: a semelhança do instrumento com a PPP ${ }^{3}$ (MARICATO; FERREIRA, 2002, p. 130).

O que se percebe pelas experiências atuais baseadas em OUC's é a intensa privatização do planejamento, em decorrência do controle do mercado sobre a condução das prioridades de gestão das OUC's e na viabilização dos investimentos com os recursos captados, e logicamente, na manipulação dos Conselhos Gestores na aprovação da utilização dos recursos conforme preferem os investidores privados ${ }^{4}$ (FIX, 2009, p.55).

A apropriação e realização da OUC como instrumento de mercado e não de planejamento democrático, conforme desenhado pelo Estatuto da Cidade, só é possível pela encriptação de poder, conforme apresentado, pois ela permite a manipulação técnica do instrumento pelo simulacro de democracia controlando os interesses sociais e públicos.

A leitura pela encriptação poderia fechar a possibilidade de utilização do referido dispositivo político-jurídico no planejamento urbano. Entretanto, com base na noção de ideologia constitucional adotada, é possível resgatarmos a plenitude do contexto normativo que baseia a OUC e os demais instrumentos de políticas urbanas.

\begin{abstract}
A "ideologia constitucionalmente adotada" está relacionada ao texto constitucional, mas não se resume ao texto. Ao interpretar os preceitos da "ordem econômica" e seus princípios, o jurista reinterpreta os seus significados linguísticos, de modo a propor um novo horizonte semântico ao texto constitucional. Em uma sociedade aberta e plural, a relação hermenêutica não se manifestada estritamente na relação sujeito-texto, mas no ciclo dialógica entre sujeito-texto-sociedade. Em resumo, o texto constitucional é apenas o ponto de partida para a interpretação da ordem econômica. O processo de concretude do texto representa também um cíclico processo de abertura aos novos significados do próprio texto.

Ora, caso concordemos com essa tese, a questão central consiste em compreender que a "ideologia constitucionalmente adotada" é uma categoria aberta a novas significações e sentidos, pois o conteúdo da ideologia constitucionalmente adotada não se restringe a leitura e interpretação literal dos princípios de ordem econômica.

Em segundo, a "ideologia constitucionalmente adotada" não constituí apenas um conjunto de princípios e normas de cunho liberal e social que visam prescrever um modelo normativo-axiológico ao sistema econômico capitalista. Ao contrário do conceito original, a "ideologia constitucionalmente adotada" deve estar aberto ao conceito de "economia" em seu sentido lato, no qual constam relações mercantis (típicas de uma economia de mercado) e relações não-mercantis (relações nas quais outros princípios organizadores da vida econômica estão presentes, tais como, a solidariedade, a dádiva, etc.). Desta forma, não se concebe a possibilidade da existência de antinomia da norma jurídica entre os comandos originais da constituição econômica (CLARK, CORRÊA, NASCIMENTO, 2013, p. 280-281)
\end{abstract}

\footnotetext{
${ }^{3}$ COTA (2011, p.148) demonstra que as OUCs em Belo Horizonte, geram as renovações espaciais voltadas ao mercado, mas não cumprem seus interesses sociais e públicos. A crítica fundamental corresponde ao papel legitimador do interesse público na criação e justificação da OUC.

${ }^{4}$ Nas experiências de OUC na cidade de São Paulo, FIX (2009, p.56), percebeu que os Conselhos Gestores eram montados com predominância de atores relacionados aos investidores, enquanto a representatividade das populações locais, era diminuída.
} 
A ideologia constitucional adotada desvelada do contexto normativo do direito à cidade encontra respaldo na combinação dos artigos $5^{\circ}, 6^{\circ}, 182$ e 225 da nossa Lei Maior de 1988 e do artigo $2^{\circ}$ do Estatuto da Cidade. Assim, a partir da leitura dos dispositivos enviesados pela ideologia constitucional, promove-se a leitura técnica e jurídica capaz de negar o avanço da OUC como instrumento de mercado e recuperá-la como instrumento democrático de planejamento urbano, pois se torna tecnicamente impossível dissociar o seu uso como formas qualitativas de participação popular na gestão naquela.

\section{CONSIDERAÇÕES FINAIS}

A governança empreendedora foi amplamente recepcionada pela administração publica brasileira a partir dos anos 90 do século passado, reduzindo os instrumentos de planejamento urbano aos desejos mercadológicos empresariais, inclusive "remodelando" cidades destinadas a grandes espetáculos (Copa de 2014 e Olimpíadas de 2016) sempre com a preocupação dos ganhos do capital.

A consolidação do planejamento neoliberal regulador só foi possível em decorrência da encriptação operada no direito, que impede a realização do próprio direito centrado na perspectiva democrática (plena, social e plural), ao transforma-la em simulacro para legitimar a privatização das políticas e dos solos urbanos.

Desse modo, a definição de ideologia constitucional adotada contribui para a recuperação dos instrumentos de política urbana, por meio da reapropriação democrática. Pois, ela oferece o recurso técnico-jurídico para desencriptar o direito e abri-lo para a democracia popular e social ditada pela Constituição brasileira de 1988.

\section{REFERÊNCIAS BIBLIOGRÁFICAS}

BERCOVICI, Gilberto. Constituição Econômica e Desenvolvimento: uma leitura a partir da Constituição de 1988. São Paulo: Malheiros, 2005.

BRASIL. Constituição (1988). Constituição da República Federativa do Brasil. Brasília: Senado Federal, 1988.

BRASIL. Estatuto da Cidade (2001). Lei no 10.257, de 10 de julho de 2001. Regulamenta os arts. 182 e 183 da Constituição Federal, estabelece diretrizes gerais da política urbana e dá outras providências. Diário Oficial da União, Brasília, 11 de jul. 2001. Disponível em:

http://www.planalto.gov.br/ccivil_03/leis/leis_2001/110257.htm. Acesso em 10 nov. 2014. 
BRASIL. Estatuto da Metrópole (2015). Lei no 13.089, de 12 de janeiro de 2015. Institui o Estatuto da Metrópole, altera a Lei no 10.257, de 10 de julho de 2001, e dá outras providências. Diário Oficial da União, Brasília 13 jan. 2015.

BRASIL. Medida Provisória (2016). Medida Provisória n ${ }^{\circ}$ 727, de 12 de maio de 2016. Cria o programa de Parceria de Investimentos - PI e dá outras providências. Diário Oficial da União, Brasília, 12 maio 2016.

BRASIL. Lei da Parceria Público-Privada (2004). Lei no 11.079 de 30 de dezembro de 2004. Institui as normas gerais para licitação e contratação de parceria público-privada no âmbito da administração pública. Diário Oficial da União, Brasília, 31 dez. 2004.

CAMARGO, Ricardo Antonio Lucas. Curso Elementar de Direito Econômico. Porto Alegre: Nuria Fabris, 2014.

CLARK, Giovani. Política Econômica e Estado. In: SOUZA, Washington Peluso Albino de. CLARK, Giovani. Questões Polêmicas de Direito Econômico. São Paulo: LTr, 2008

CLARK, Giovani. O pioneirismo da Faculdade de Direito da UFMG: a introdução do Econômico. Revista Brasileira de Estudos Políticos, v. 40, 2012, p 143 a 156.

CLARK, Gionvani; CORRÊA, Leonardo Alves; NASCIMENTO, Samuel Pontes do. Ideologia Constitucional e Pluralismo Produtivo. Revista da Faculdade de Direito da UFMG. v. Especial, 2013 , p. 265 a 300.

COTA, Daniela Abritta. Descompassos entre o discurso e a prática das operações urbanas em Belo Horizonte (1997-2008). In. COSTA, Heloísa de Moura; MENDONÇA, Jupira Gomes de (orgs). Estado e Capital imobiliário: convergências atuais na produção do espaço urbano brasileiro. 1 ed. Belo Horizonte: C/Arte, 2011.

FERNANDES LIMA, Bruno. Função social da propriedade: entre o simbólico e o encriptado. 2015. Monografia. Faculdade Mineira de Direito. PUC Minas.

FIX, Mariana. Uma ponte para a especulação. Caderno CRH. Salvador, UFBA, v. 22, n. 55, 2009. Disponível em: http://www.cadernocrh.ufba.br/viewarticle.php?id=622\&layout=abstract. Acesso em 15 de set. 2015.

FRIEDMANN, John. Planning in the Public Domain: from knowledge to action. Princeton: Princeton U. Press, 1987.

GRAU, Eros Roberto. A Ordem Econômica na Constituição de 1988. 14 ed. São Paulo: Malheiros, 2010.

GUSMÃO, Paulo Dourado de. Introdução ao Estudo de Direito. $23^{\circ}$ ed. Rio de Janeiro: Forense, 1998.

HARDT, Michael; NEGRI, Antonio. Império. 9. ed. Rio de Janeiro: Record, 2010.

HARVEY, David. A produção capitalista do espaço. 1. ed. São Paulo: Annablume, 2005.

INSTITUTO BRASILEIRO DE GEOGRAFIA E ESTATÍSTICA. Perfil dos municípios brasileiros: gestão pública, 2005. Rio de Janeiro: IBGE, 2006. Disponível em:

http://www.ibge.gov.br/home/estatistica/economia/perfilmunic/2005/munic2005.pdf. Acesso em: 10 de fev. 2014. 
INSTITUTO BRASILEIRO DE GEOGRAFIA E ESTATÍSTICA. Perfil dos municípios brasileiros: 2013. Rio de Janeiro: IBGE, 2014. Disponível em:

ftp://ftp.ibge.gov.br/Perfil_Municipios/2013/munic2013.pdf . Acesso em: 10 de fev. 2014.

MAGALHÃES, Felipe Nunes Coelho. O neoliberalismo e a produção do espaço na metrópole: subjetividade, insurgências e redes na economia politica da urbanização contemporênea. 2015. 271 f., enc. Tese (doutorado) - Universidade Federal de Minas Gerais, Departamento de Geografia.

MARICATO, Ermínia; FERREIRA, José Sette Whitaker. Operação Urbana Consorciada: diversificação urbanística participativa ou aprofundamento da desigualdade? (In) Osório, Letícia Marques (org.). Estatuto da Cidade e Reforma Urbana: novas perspectivas para as cidades brasileiras. 1 ed. Porto Alegre: Serio Antonio Fabris Editor, 2002.

MENDÉZ HINCAPÍE, Gabriel; SANÍN RESTREPO, Ricardo. La constitución encriptada: nuevas formas de emancipación del poder global. Revista de Derechos Humanos y Estudios Sociales, Sevilla, n. 8, dez. 2012. Disponível em: <http://www.uaslp.mx/Spanish/Academicas /FD/REDHES/Documents/N\%C3\%BAmero\%208/Redhes8-05.pdf > . Acesso em 05 out 2014

MONTANDON, Daniel Todtmann. Operações urbanas em São Paulo: da negociação financeira ao compartilhamento equitativo de custos e benefícios. 2009. Dissertação (Mestrado em Planejamento Urbano e Regional) - Faculdade de Arquitetura e Urbanismo, Universidade de São Paulo, São Paulo, 2009. Disponível em: http://www.teses.usp.br/teses/disponiveis/16/16139/tde-19032010-111532/. Acesso em: 10 de set. 2015.

MOURA, Rosa; PEGO, Bolívar. Aglomerações Urbanas no Brasil e na América do Sul: trajetórias e novas configurações. Textos para discussão. Brasília: Instituto de Pesquisa Econômica Aplicada. 2016. Disponível em: < http://goo.gl/NXI5t0 >. Acesso em 26 de julho de 2016

NADALIN, Vanessa Gapriotti; Cleandro Krause; LIMA NETO, Vicente Correia. Distribuição de Aglomerados Subnormais na Rede Urbana e nas Grandes Regiões Brasileiras. In. Caracterização e tipologia de assentamentos precários: estudos de casos brasileiros. Org. MORAIS, Maria da Piedade; KLAUSE, Leandro; LIMA NETO, Vicente Correia. Brasília: Instituto de Pesquisa Econômica Aplicada. 2016. Disponível em: http://goo.gl/9LFTSy. Acesso em 26 de julho de 2016

OLIVEIRA, Fabrício Augusto de. Economia e política das finanças públicas no Brasil: um guia de leitura. São Paulo: Hucitec. 2009.

OSÓRIO, Letícia Marques. The social function of property. 2013. Disponível em: http://www.righttothecityplatform.org.br/. Acesso em 15 nov. 2014.

SANTOS, Boaventura de Sousa. A gramática do tempo: para uma nova cultura política. 2. ed. São Paulo: Cortez, 2008. 512 p.

SANÍN RESTREPO, Ricardo. Teoría crítica constitucional: la democracia a la enésima potencia. 1 ed. Valencia: Tirant Lo Blanch, 2014.

SOUZA, Marcelo Lopes de. Mudar a cidade: uma introdução crítica ao planejamento e à gestão urbanos. 5 ed. Rio de Janeiro: Bertrand Brasil, 2008.

SOUZA, Washington Peluso Albino. Primeiras linhas de direito econômico. $6^{a}$ ed. São Paulo: LTr, 2005.

SWYNGEDOUW, Erik. Privatizando H20: transformando águas locais em dinheiro global. Revista Brasileira de Estudos Urbanos e Regionais, v. 6, n. 1, 2004. 